\title{
ENTREVISTA COM RUY BRAGA
}

Realizada por Nicolau Dela Bandera e Leonardo Fontes

Pouco antes de partir para uma temporada de um ano na Universidade de Berkeley, nos Estados Unidos, o professor Ruy Gomes Braga Neto recebeu a Revista Plural em sua sala para uma entrevista, em agosto de 2010. Em uma conversa de pouco mais de uma hora, ele falou sobre sua formação fortemente influenciada pelo "caldo marxista da UNICAMP" - segundo palavras do próprio autor - e sobre a relação entre suas pesquisas teóricas e empíricas. Ruy Braga nos falou também sobre as dificuldades do marxismo na atual conjuntura político-acadêmica e contou como se deu sua aproximação com a Sociologia pública, fazendo um convite para que os estudantes de Sociologia no Brasil se apropriem dessa nova agenda internacional de pesquisa.

Revista Plural Gostaríamos de começar agradecendo por receber a Revista Plural para esta entrevista.

Ruy Braga Sou eu que tenho que agradecer, gente!

Revista Plural Gostaríamos que vocêfalasse brevemente sobre sua formação. Ruy Braga Eu tenho uma formação acadêmica absolutamente concentrada em uma instituição, que é a Universidade Estadual de Campinas; quer dizer, eu fiz minha graduação, meu mestrado e meu doutorado na UNICAMP... Eu, na verdade, entrei na Universidade de Campinas em 1990. Do meu período de formação, eu posso destacar duas coisas. A primeira delas é que a UnICAMP, nesse momento do final dos 1980 e começo dos 1990 - eu não sei como está hoje -, na época, era uma universidade muito vibrante e com uma 
concentração de intelectuais com uma formação crítica nas mais diferentes áreas: Sociologia, Ciência Política, Antropologia, História, Filosofia. Então, a UnICAMP era um centro proeminente de reflexão crítica e onde o marxismo, no âmbito das Ciências Sociais, acomodou-se de uma forma bastante interessante. Eu costumo brincar que, em parte da minha trajetória na graduação, eu achava que teoria social ou teoria sociológica se resumia às polêmicas entre os lukácsianos versus gramiscianos versus os poulantzanianos versus althusserianos versus os thompsonianos... Ou seja, teoria social era alguma coisa entre Thompson e Althusser, passando pelas mais diferentes correntes do marxismo. Cabe destacar a presença muito interessante e marcante do Otávio Ianni na UnicAmp, que foi meu professor. Eu fui muito assíduo em seus cursos. Ele era uma figura muito carismática, muito magnética e interessante. Ele teve um peso enorme na formação de toda uma geração de sociólogos críticos na Universidade. Além do grupo de marxistas do Departamento de Sociologia, tendo à frente Ricardo Antunes, Edmundo Fernandes Dias, Ângela Tude, gente de muita boa qualidade, além de colegas das mais diferentes áreas, como, por exemplo, o Departamento de História da UNICAMP, que é muito marcado pelo tema e as questões da história social do trabalho. Da mesma maneira, o IFCH acomoda há muitos anos o Arquivo Edgard Leuenroth, que é o principal arquivo de documentação da história do movimento operário brasileiro. E com uma biblioteca que foi em grande parte formada pelo Michael Hall, que é um proeminente historiador do trabalho. Então, isso tudo acabou me influenciando; esse ambiente intelectual me influenciou nas escolhas que eu fiz de pesquisa no doutorado, no mestrado e na graduação, que foi uma pesquisa focada nas mudanças no mundo do trabalho no setor metalúrgico de Campinas, impactos que isso tinha na questão da exploração do trabalho, as condições de trabalho, a consciência do trabalhador. Depois eu deixei de lado esse tipo de trabalho que tinha uma natureza mais empírica e me interessei por uma pesquisa teórica, cuja principal preocupação era uma reflexão a propósito daquilo que a gente poderia cha- 
mar de debate internacional na Sociologia sobre a reestruturação produtiva e as transformações no mundo do trabalho. Eu acabei me concentrando em uma espécie de balanço crítico da obra do André Gorz, que é um autor muito influente nesse campo de estudo.

\section{Revista Plural Isso no mestrado?}

Ruy Braga Sim, no mestrado. E acabei ampliando no mestrado para outras correntes que dialogavam com a perspectiva da crise do trabalho, entre as quais a mais conhecida seguramente é a de Michael Piore e Charles Sabel, The Second Industrial Divide: Possibilities For Prosperity, e fiz uma tentativa de análise crítica desses textos. Enfim, daquele debate que a gente pode chamar da crise do trabalho, da reestruturação produtiva, das metamorfoses do trabalho muito marcado pela presença do André Gorz. Meu doutorado foi dedicado também a um projeto teórico de análise e balanço da trajetória da Escola Francesa da Regulação. Foi um doutorado muito concentrado também em uma perspectiva de análise teórica do mundo do trabalho, mas mais concentrada na trajetória da Escola da Regulação, que é bastante influente nas Ciências Sociais de uma maneira geral e, no Brasil, teve relativamente pouca repercussão, se você comparar com outros países, mesmo na América Latina, como a Argentina e o México, a despeito de dialogar de uma maneira muito forte com a chamada (abre aspas) "Escola de Campinas", nos estudos sobre Economia do Trabalho e sobre o modo de desenvolvimento capitalistas no Brasil, que foram desenvolvidos pelo professor João Manuel [Cardoso de Mello], pelo professor [Luiz Gonzaga] Beluzzo, pelo grupo do Cesit da Unicamp. Então, você tem aí uma série de preocupações que me levaram a escolher essa equipe de economistas, a chamada Escola Francesa da Regulação. Eu me concentrei mais no trabalho dos economistas da primeira e da segunda geração, mas fiz um balanço do conjunto das questões teóricas e dos deslocamentos, e o eixo da minha tese de doutorado foi uma tentativa de compreender por que a teoria da regulação dos anos 1970 se transfor- 
ma em uma técnica de regulação nas décadas de 1980 e 1990. Eu fiz isso a partir de uma análise da trajetória da teoria da regulação, muito concentrada em uma inspiração gramsciana, discutindo a questão dos intelectuais, o problema da inserção dos regulacionistas no campo político de uma maneira geral, em especial no aparelho de Estado. Enfim, tentando articular as trajetórias dos regulacionistas com os deslocamentos teóricos, a própria presença deles no aparelho do Estado, com as transformações políticas, em especial com o advento da Frente Popular e da vitória do Miterrand, a guinada do Governo Miterrand, em 1981-1982. Isso tudo foi um pouco minha preocupação na "Nostalgia do Fordismo", que é o título da minha tese de doutorado. É um pouco essa minha formação, tanto a influência do marxismo na UNICAMP, e, nesse sentido, é bem interessante que eu nunca me considerei dogmático, até porque eu fui formado em um ambiente que misturava uma quantidade imensa de correntes dentro do marxismo. A gente estava sempre muito envolvido com muitos debates e muitos autores e muitos intelectuais que dialogavam com diferentes autores, quer dizer, Lukács, Thompsom, Gramsci, Althusser, Poulantzas. Isso tudo fazia parte do universo e repercute tanto no meu interesse de pesquisa na graduação por um trabalho empírico sobre o setor metalúrgico de Campinas - eu fiz pesquisa em duas empresas pequenas -, depois em meu interesse em estudar André Gorz no mestrado e, por fim, estudar a Escola da Regulação no doutorado. Essa é minha trajetória intelectual na UNICAMP.

Revista Plural Surgiu uma questão nessa sua ótima explanação sobre aquilo que te influenciou. Uma questão sobre a relação entre o marxismo e as Ciências Sociais e sobre como você concilia, em seus trabalhos mais recentes, a teoria e a empiria. No marxismo ocidental, na teoria crítica, por vezes nós temos trabalhos que são de fôlego teórico, mas, quando vão abordar estudos de caso, eles acabam se perdendo. Nessa sua trajetória, como você lidou com essa relação entre teoria e empiria? 
Ruy Braga Em primeiro lugar, sobre a questão do marxismo e as Ciências Sociais eu diria que existe, de fato, certa interpretação do marxismo, em especial no Brasil, que tende a inseri-lo em uma espécie de longo e inesgotável discurso a propósito da investigação dos fundamentos e dos pressupostos metodológicos da teoria pela teoria e que, em minha opinião, acaba se traduzindo em uma espécie de dogmática marxista, muito autocentrada, autorreferente e que acaba por se afastar daquilo que eu considero essencial para revivificação do marxismo, que é o diálogo com os dados, o marxismo como um instrumento de interpretação científica da realidade, em especial aquele que eu chamo de marxismo sociológico. E o marxismo brasileiro, infelizmente, acabou nas décadas de 1970 e até meados da década de 1980, em certo sentido, empobrecendo-se, ao se afastar do diálogo com os dados e as pesquisas empíricas. Não era assim, mesmo se você levar em consideração o famoso seminário Marx aqui na USP, que é uma espécie de experiência de marxismo (abre aspas) “ocidental”, em uma situação muito peculiar, que é da década de 1960, você vai perceber que evidentemente existia, de um lado, uma preocupação teórica e metodológica, vamos dizer assim, bastante rigorosa, em termos de abstração e de conceitualização, que é um pouco aquilo que o Ruy Fausto, o Giannotti e alguns outros fizeram. Mas existia, de outro lado, uma tradição que se abria para as pesquisas empíricas, que se organizou em torno de um projeto intelectual e investigativo de larga escala, que envolvia a análise do Estado com o Ianni, dos empresários com o Fernando Henrique, que se abria para os estudos da área de Sociologia do trabalho. Estava presente o próprio Leôncio [Martins Rodrigues], que, a despeito de não fazer parte do grupo original foi logo convidado a participar desse seminário. Ela já era um experiente estudioso da área do trabalho por razões políticas. Então, você tinha uma espécie de divisão intelectual do trabalho, em que uns pensavam a teoria e outros traduziam essa teoria em pesquisas empíricas. Infelizmente, o contexto da Ditadura, de um lado, e as próprias características político-partidárias brasileiras, o tipo de influência stalinista que se tinha fizeram com 
que esses estudos empíricos fossem ficando menos importantes, e o marxismo acabou se distanciando dessa agenda mais empírica. Eu, de qualquer forma, a minha graduação nem tanto, mas meus dois estudos de mestrado e doutorado refletem um pouco isso. Quando eu fui escolher um objeto para estudar, eu acabei escolhendo André Gorz e a Escola da Regulação. Eu também faço parte desse problema. Entretanto, eu tentei, de alguma maneira, corrigir a rota e abrir meu horizonte pessoal para a pesquisa empírica. Hoje eu considero absolutamente essencial. Uma reflexão marxista rica não pode prescindir de um diálogo com os dados, consequentemente, não pode abrir mão da excelência das técnicas investigativas, e não ser apenas uma reflexão teórica a propósito dos métodos. Eu acho isto de fundamental importância: para que o marxismo possa se desenvolver hoje; ele não pode apenas se abrir e dialogar criticamente com as mais diferentes correntes, inclusive da Sociologia... Eu, vamos dizer assim, sempre reiterei a necessidade de o marxismo dialogar com a Sociologia crítica. Isso é algo absolutamente essencial, são duas correntes do pensamento que se complementam em muitas ocasiões, que podem se enriquecer, que possuem contradições e diferenças, têm tensões, mas devem estar em permanente contato, de um lado. Porém, mais do que isso, eu acho que o marxismo só vai poder avançar se ele incorporar aquilo que existe de mais sofisticado, aquilo que existe de mais rico e avançado nas técnicas que as ciências sociais têm promovido. Eu, evidentemente, não entendo que as técnicas sejam neutras, porém o marxismo não pode se furtar de incorporar a excelência das técnicas ao seu cabedal, escopo, seu instrumental. Isso é questão de vida ou morte para o marxismo brasileiro. Eu tenho insistido muito nisso e acho que isso me inspirou a propor com outros colegas, em especial com Armando Boito, Álvaro Bianchi, do grupo de trabalho na AnPocs, chamado Marxismo e Ciências Sociais. 
Revista Plural Eu queria aproveitar sua resposta anterior, que você falou sobre todo esse caldo marxista que existia na UNICAMP. Eu queria perguntar qual foi o cenário que você encontrou na USP.

Ruy Braga Eu diria para você que hoje, evidentemente, o marxismo não é uma corrente predominante nas Ciências Sociais da USP, também não é no Departamento de Sociologia da USP. Aliás, o marxismo não é uma corrente predominante em lugar nenhum do mundo, diga-se de passagem. Talvez com uma ou outra exceção na América Latina, na Venezuela, Argentina... Mas a rigor o marxismo não é uma corrente predominante. O marxismo tem um espaço nas Ciências Sociais, afinal de contas, o Marx é um dos clássicos, ele tem um espaço no campo da política e, evidentemente, na política universitária. Porém, eu entendo que, no Departamento de Sociologia, em sua história e trajetória, ele foi absolutamente fundamental para assentar as bases do que se tem hoje, digamos assim, de produção teórica e de pesquisa daquilo que se reivindica de marxismo hoje no Brasil. Ele tem uma importância absolutamente fundamental. Hoje, o marxismo está distante de ser uma corrente predominante, porém ele se acomoda, de alguma maneira... Eu diria para você, de uma forma muito sintética, que o Departamento de Sociologia configura um capítulo muito importante da história do marxismo brasileiro; ele faz parte da história do marxismo brasileiro, de uma forma absolutamente central e, hoje, a despeito de não ser um departamento predominantemente marxista, ele não é refratário ao marxismo, porque o departamento tem uma característica crítica, a Sociologia crítica é aquela que vertebra os programas de pesquisa, em suas mais diferentes correntes. Como eu entendo que a Sociologia crítica deve se abrir e pode manter contatos e fronteiras com o marxismo, eu vejo que o departamento não é refratário ao marxismo, ele reconhece a importância do marxismo nas ciências sociais, no próprio departamento e, ao mesmo tempo, reconhece a utilidade do marxismo como instrumento de pesquisa. O marxismo hoje está muito concentrado no $\mathrm{CE}$ NEDIC, mas, mais recentemente, nós temos experiências importantes com a 
formação do Laboratório de Estudos Marxistas, de que o Ricardo Musse é o principal representante. O Ricardo tem feito um trabalho de longa data de valorização da teoria crítica, de Lukács, Escola de Frankfurt, isso faz com que a tradição do marxismo na USP se mantenha viva dentro do Departamento de Sociologia.

Revista Plural Ainda dentro da discussão sobre a relação entre marxismo e Sociologia, quando você encontrou o marxismo nos EUA?

Ruy Braga Olha, eu sou um leitor do marxismo dos EUA desde minha graduação, quando eu me interessei pelos estudos do trabalho, da Sociologia do trabalho; eu me interessei muito pelo debate Braverman e pós-Braverman. Então, a Sociologia e o marxismo americano entraram na minha formação por meio de Braverman, que foi, junto com Gramsci, no sentido mais geral, e o Braverman, no sentido mais específico, os autores que mais me influenciaram durante minha graduação. Eu passei minha graduação lendo e relendo o livro Trabalho e Capital Monopolista, da mesma maneira que eu lia e relia Os Cadernos do Cárcere. Então, é o núcleo da leitura marxista de minha graduação. Nesse sentido, eu sempre tive muita afinidade com o marxismo americano. Pelo fato de eu ter escolhido como objeto de mestrado e de doutorado autores franceses, eu acabei, evidentemente, ambientando-me com o marxismo na França. Eu passei algumas temporadas de pesquisa na França, em especial no Grupo da Revista Actuel Marx, mas não apenas; passei uma temporada no IrEs [Instituto de Pesquisa Econômico e Social], Nantèrre. Eu acabei me aproximando do marxismo na França, em um momento em que ele estava se renovando de uma maneira muito interessante. Era um momento pós-crise do Stalinismo, meados da década de 1990, o movimento social na França estava se revificando, ao mesmo tempo em que o marxismo passava por um momento de desgelo, de muita reflexão. Os congressos Marx internacional começaram a acontecer, acho que em 1997, 1998 (eu nunca tenho essas datas na cabeça). Eu lembro que aquele ambiente intelectual crítico e re- 
novado foi muito interessante. Essas escolhas de mestrado e doutorado, que absorvem a gente durante um largo período de tempo, acabaram me tencionando para outro horizonte nacional de produção intelectual marxista. Mas não que eu abandonei minhas leituras, tanto que, no mestrado, eu lia muito Burawoy, em especial The Politics of Production, um texto que eu sempre gostei bastante. Da mesma maneira que outros autores, considerados (abre aspas) "heterodoxos" do marxismo, em especial Perry Anderson, que é um autor que também leio com muita frequência há muitos anos, quase duas décadas. Então, são dois autores ingleses que trabalham e moram nos EUA há muitos anos. O marxismo americano sempre esteve presente na minha vida por outro motivo, que não tem nada a ver com a universidade, quer dizer, tem relação indireta. Eu faço parte de uma tradição política no marxismo, o chamado trotskismo, para simplificar um pouco, que se desenvolveu durante as décadas de 1930, 1940, 1950, 1960, de uma forma muito intensa nos EUA. Então, você tem uma longa etapa de produção intelectual, desde os militantes, propriamente falando, James Cannon, o pai do trotskismo americano, passando pelas cisões, James Burnham, originalmente trotskista, mas depois rompe com o trotskismo e, que, nesse processo, publica o livro Revolução Gerencial, que é um livro muito interessante e que influenciou muitos estudos na área do trabalho, passando por autores importantes, como George Novack, na Filosofia, e tantos outros que estavam presentes nas minhas leituras como militante de partido político trotskista e aquela coisa toda. Então, por esse lado, eu sempre me mantive próximo do marxismo americano. Outra área interessante, que eu não fui especialista, mas que sempre me interessou e que talvez valha a pena citar, é que eu tive a oportunidade de ser aluno, na UniCAMP, em um curso que eu fazia na pós-graduação, do Leôncio [Martins Rodrigues], sobre sindicalismo e trabalho. Tinha um professor inglês visitante, que hoje está na Universidade de Cardiff e que escreveu um livro muito influente, chamado Working for Ford, que, ainda hoje, acredito eu, se considera um marxista, chamado Huw Beynon. Ele é um sociólo- 
go do trabalho muito interessante, que tem muitos contatos nos EUA e no marxismo anglo-saxão. E, finalmente, autores tão importantes como Mike Davis, Fredric Jameson, que são autores sempre presentes na discussão sobre trabalho, mesmo no meu mestrado e no doutorado, uma figura como o David Harvey foi uma pessoa-chave. Da mesma maneira, leituras como a do Arrighi, que, apesar de ser italiano, morou muitos anos nos EUA. Então, eu queria realçar: isso pode parecer confuso, que é impossível ser marxista e ter uma formação teórica marxista, sem se envolver com essas duas escolas - uma a Escola estadunidense, que possui uma larga tradição e que, a partir de 1968, ganha densidade e complexidade em todas as áreas, nos estudos sobre os processos de trabalho, passando pela área de estratificação social e das classes sociais, como Erik Olin Wright, chegando à área da historiografia e dos estudos culturais, literários, com Jameson e tantos outros; e a Escola francesa, com sua larga tradição e também muito influenciada pelo pós-1968, que vem da crise do marxismo althusseriano, mas que incorpora Poulantzas e que depois viu emergir autores da estatura de um Daniel Bensaid, com uma tradição na Sociologia, com Pierre Naville, que têm diálogos transversais com diferentes áreas do conhecimento, com a Filosofia, a História, a Antropologia. Tem autores como Claude Meillassoux, que não era propriamente francês, mas dialogava com a França, Maurice Godelier... Emmanuel Terray. O que eu quero dizer é que não dá para ser marxista sem beber destas fontes: o marxismo americano e o marxismo francês. São autores absolutamente importantes do marxismo e, diga-se de passagem, que, com muita dificuldade, se encontram entre eles. Normalmente quem faz essa triangulação são os latino-americanos; outra curiosidade.

Revista Plural Como você se aproximou do tema da Sociologia pública? Qual é sua visão da Sociologia pública e o que a diferencia de outros modelos de intelectual, tal como o intelectual orgânico de Gramsci ou até mesmo o de intelectual militante, como Florestan Fernandes? 
Ruy Braga A Sociologia pública entrou na minha vida em 2004, quando eu passei a fazer parte de uma associação internacional de Sociologia, chamada Sociologists Without Borders (Sociólogos Sem Fronteiras), por intermédio da Judith Blau, que, na época, era a presidente da associação, junto com Alberto Moncada, um colega da Espanha, mas que deu aulas durante muitos anos na Universidade da Flórida. Eu, junto com outros colegas daqui do Brasil, dentre os quais Paulo Roberto Martins, um velho amigo, fiz parte da direção do Sindicato dos Sociólogos de São Paulo... Nós nos sentimos muito atraídos pela proposta da Associação e passamos a fazer parte dessa associação, animando encontros, participando da revista, dos debates, a página na internet, etc. A Judith tem um livro sobre Sociologia pública, um reader, muito interessante... Esse é o reader da incansável ativista social Judith: Public Sociologies Reader. De Judith Blau Keri E. Iyall Smith. E, nesse momento, que era 2004-2005, eu trouxe a Judith para o Brasil, fizemos algumas atividades, e eu passei a efetivamente não apenas desenvolver atividades dentro dessa associação, mas também a refletir sobre qual era a teoria que estava por trás de uma associação como essa, Sociólogos Sem Fronteiras. Nesse contexto, eu tive contato com os textos de Burawoy. Ele tinha sido eleito presidente da Associação de Sociologia Americana. Eu acabei me aproximando do Michael [Burawoy] pela Judith, que me apresentou via e-mail. Trocamos e-mails, nasceu uma amizade, e eu convidei o Michael a participar do encontro da SBS, não me lembro em que ano, em Recife. Eu organizei um debate entre ele e mim em um encontro de Recife e, a partir daí, eu passei a trabalhar em uma agenda mais ou menos comum de reflexão e pesquisa. Então, é um pouco essa minha relação com a Sociologia pública do ponto de vista institucional, digamos assim. Do ponto de vista teórico, eu diria para vocês que a Sociologia pública é um estilo de se fazer Sociologia que procura articular duas dimensões de nosso campo disciplinar: uma primeira dimensão que poderíamos chamar de teórica e epistemológica, ou seja, um profundo compromisso com a Sociologia crítica e reflexiva, aquela que efetivamente 
se propõe a refletir a propósito não apenas dos fins, mas também dos meios, que se aproxima muito de uma modelo de reflexão crítica que foi largamente desenvolvido pela escola de Frankfurt; talvez a síntese mais interessante seja propriamente o texto "Teoria tradicional e teoria crítica”, que se encontra na Dialética do Esclarecimento ${ }^{1}$, mas que também não se limita a um diálogo com audiências acadêmicas, ou seja, a Sociologia pública se nutre de uma dinâmica, eu diria, centrada com as audiências extra-acadêmicas. Evidentemente, ela parte de um universo acadêmico. O primeiro público, como o próprio Burawoy sempre enfatiza, são os estudantes de Sociologia; ele é o primeiro e o mais privilegiado público que nós temos, é inesgotável, sempre existirão e serão eles que levarão a Sociologia adiante, inclusive a própria Sociologia pública, mas que não se esgota nesse encapsulamento ou naquilo que muitos chamam de especialização da Sociologia profissional. Ou seja, ela procura se nutrir da excelência das técnicas que a Sociologia profissional desenvolve e procura dialogar de maneira fraterna com a Sociologia crítica, mas que tem como horizonte de intervenção e de diálogo, de participação e de compromisso político as audiências extra-acadêmicas, em especial os movimentos sociais progressistas e a esfera progressista da sociedade civil. Todos nós sabemos que o conceito de sociedade civil é tenso, ambivalente, contraditório, complexo, porém esse é um pouco o terreno no qual a Sociologia pública se dispõe, digamos assim, a atuar. Nesse sentido, essa me parece uma prática, digamos assim, muito orientada por um profundo compromisso político. Eu acho que essa é a principal característica da Sociologia pública, e me parece que essa preocupação com a reflexão crítica e, ao mesmo tempo, essa contextualização política das práticas sociológicas têm ganhado uma audiência internacional, ou seja, não é à toa que o próprio Michael Burawoy tenha sido agora eleito o presidente da International Sociological

1 Na realidade, esse texto se encontra publicado no Brasil, na coletânea Teoria Crítica I, da Editora Perspectiva. 
Association, nesse congresso de Gotemburg, isso não é algo nem inocente nem tampouco acidental. Eu, pessoalmente, o meu projeto na área de Sociologia pública e que sempre teve relação com a Sociologia pública do trabalho, etc., eu continuo fazendo; são minhas pesquisas sobre os trabalhadores no setor de serviços, minhas pesquisas sobre movimento sindical; isso eu continuo fazendo com muita tranquilidade. Teoricamente, eu, na verdade, tinha um projeto, intelectualmente falando, de buscar localizar a Sociologia marxista, ou o marxismo sociológico, como eu costumo dizer, no interior desse quadrante da Sociologia pública, uma espécie de tentativa de construir uma Sociologia pública marxista, porque no Brasil, como em outros contextos nacionais mundo afora, o marxismo - aquilo que o Goran Therborn chama de o triângulo quebrado do marxismo -, ou seja, a crise do stalinismo acabou fazendo com que o marxismo como prática política tenha se esfacelado, esfarelado, e o tripé do marxismo sociológico, que envolvia, dentre outras coisa, uma epistemologia crítica de uma lado e uma ciência social do outro, também se esfacela, passa por um processo de crise. Parece-me que uma maneira de articular isso tudo novamente - evidentemente que eu estou me referindo aqui ao marxismo sociológico, se eu estivesse falando aqui sobre a Economia Política marxista ou a Antropologia marxista, seria outra discussão -, no marxismo sociológico, é por meio da Sociologia pública, que é o melhor quadrante que acolhe o marxismo sociológico, pois o marxismo sociológico perde muito se ele ficar restrito ou circunscrito à esfera universitária apenas. Eu acho que é importante, mas não é suficiente. Então, é nesse sentido que eu tento estabelecer pontes e cruzamentos entre a Sociologia pública de um lado e o marxismo sociológico de outro, porque eu considero que a Sociologia pública para um sociólogo marxista é um espaço privilegiado para se desenvolver tanto a teoria quanto o programa de pesquisa e, porque não dizer, para alicerçar um projeto político. 
Revista Plural Só para desenvolver um pouco mais a discussão sobre a Sociologia pública, nós temos uma pergunta sobre a formação do sociólogo, sobre os problemas encontrados nos programas de pós-graduação e até mesmo na graduação. Enfim, você afirmou que o primeiro público dos sociólogos são os estudantes. Como você vê hoje a pós-graduação no Brasil, a especialização precoce, a questão da produtividade?

Ruy Braga Eu acho que são dois temas. Eles estão interligados: um é o tema da graduação e o outro é o da pós e da pesquisa. Em termos de graduação, eu acho que a Sociologia pública pode ser extremamente útil para a formação do sociólogo, porque nós vivemos um momento em que a disciplina de Sociologia se torna obrigatória no Ensino Médio, o que supõe que as Licenciaturas dos diferentes cursos de Ciências Sociais no Brasil afora passem a fazer parte do próprio processo da formação do estudante do Ensino Médio, tanto do ponto de vista da reflexão a propósito de quais conteúdos da Sociologia devem estar presentes, e isso é uma discussão política por excelência, quanto a própria questão da docência, os estágios que terão que ser feitos. Os cursos de Ciências Sociais irão se responsabilizar por parte da administração desse universo, e isso tudo coloca, por assim dizer, o ensino médio como um espaço de intervenção muito importante. Como fazê-lo? Como colocar em contato estes dois universos: o universo do ensino médio e da educação de um lado, e, de outro, nossas graduações? Eu acho que a Sociologia pública pode ser muito útil nesse sentido. Eu acho que a Sociologia, por exemplo, a Sociologia da educação profissional também é importante, mas nossos estudantes de graduação acabam não se interessando pelos temas da escola, do currículo. Enfim, por uma série de motivos que nós não temos condição de desenvolver aqui, a Sociologia da educação acabou perdendo prestígio nos departamentos de Sociologia do país e foi se concentrando nas Faculdades de Educação, ela foi se especializando. Nesse sentido, há uma relativa desvalorização da Sociologia da educação, para meu desgosto, nos departamentos de Sociologia no país afora. Ficou como uma área da Pedagogia e das Licen- 
ciaturas. Então, eu acho que essa não é a melhor maneira de colocar em contato esses dois universos. A melhor maneira é transformar a escola pública em um amplo laboratório de intervenção, experimentação, de vivências políticas, intelectuais e científicas de nossos estudantes de graduação. Então, essa é uma boa discussão a ser travada, e a Sociologia pública pode oferecer esse universo epistemológico, teórico e de intervenção política e intelectual de nossos estudantes nas escolas públicas. A escola pública pode se transformar em um meio privilegiado de contato de nossos estudantes com questões as mais diferentes que você possa imaginar: mercado de trabalho, passando pela questão da violência urbana, pela questão das culturas da periferia; enfim, passando pelas mais diferentes áreas da Sociologia, você pode estabelecer pontes, contatos, utilizando a Sociologia pública como fonte de inspiração, baliza, orientação e fonte de diálogo e reflexão. Do ponto de vista da pós-graduação, a gente está no meio de uma mudança do regime de produção de conhecimento no Brasil. Quer dizer, aquele regime estatal das décadas de 1950, 1960 e 1970, com um modelo bem definido de financiamento, de investimento público, de criação de grandes laboratórios, grandes programas - concessão de bolsas, etc. - , hoje, a gente está vivendo um momento de descontinuidade e transformação. Se a década de 1990 prepara a universidade para a questão da propriedade intelectual, a década de 2000 prepara a universidade para investimento no setor privado. A universidade virou uma espécie de fonte permanente de ideias capazes de nutrir um mecanismo de inovação científica e tecnológica que está a serviço do desenvolvimento econômico, que, por sua vez, é instrumentalizado pelas grandes empresas, e assim por diante. A lei da inovação, que foi sancionada pelo Governo Lula, é uma expressão disso, pois coloca a possibilidade de os laboratórios, de os pesquisadores estarem a serviço das empresas, o que acontece com muita frequência aqui na USP, na UNICAMP e em muitos outros lugares, com as fundações, os institutos, balizados por essa matriz da inovação, o chamado sistema nacional de inovação. E você encontra isso em todas as universi- 
dades com pesquisa de ponta no Brasil hoje. Então, esse é um regime. As outras leis que foram sancionadas de estímulo privado, em termos de inovação na universidade, como, por exemplo, a "lei Haddad", a "lei do bem", todas essas leis que foram sancionadas complementam a lei da inovação e criam o arcabouço institucional para o investimento privado na universidade, enfim, para o avanço da mercantilização da ciência no Brasil, por meio desse modelo de redes, que não é mais “estatal”. Eu chamo esse regime de regime neoliberal de produção de ciência e conhecimento. Enfim, o nome pouco importa, o que importa é o tipo de conexão e relação que se dá com o universo privado, que é muito diferente do sistema estatal, que também não era perfeito, no qual se decidia burocraticamente que o país deveria investir em determinada área: a aeronáutica, e aí a primeira coisa que se fazia era criar o CTA, depois uma empresa e, depois, eventualmente, privatiza-se. É um investimento do Estado, e o CTA não será privatizado. É o Estado que dirige. O último exemplo talvez tenha sido a criação do Laboratório de Luz Síncrotron. Mas o fato é que esse regime mudou, e agora nós estamos vivendo outra situação, na qual você tem, de um lado, uma burocracia estatal que estimula um produtivismo que é a marca desse sistema de inovação, que, por sua vez, faz um esforço gigantesco para espalhar essas inovações científicas e tecnológicas e semear o setor privado, que se beneficia dos frutos desse regime. É um regime novo e que, em minha opinião, contempla pouco espaço para um tipo de conhecimento crítico, reflexivo, tudo aquilo que é a Sociologia. Vamos dizer assim, a Sociologia tem respondido a isso - eu estou falando de maneira bem geral, não é sobre o Departamento de Sociologia da USP, até porque não é essa nossa realidade -, de maneira geral, às mudanças no regime de produção de ciência e conhecimento, desenvolvendo uma espécie de face "políticas públicas”. Ela está sendo atraída por essa discussão das políticas públicas, nas mais diferentes áreas, independentemente da especialização, o que é uma estratégia, que eu acho legítima, porque legitima o conhecimento sociológico frente ao Estado e frente a certos investidores privados, porém eu 
diria para vocês que não é a única estratégia.

Revista Plural Essa estratégia é bem diferente da Sociologia pública.

Ruy Braga Eu diria para vocês que, se eu fosse sintetizar o que eu penso, a Sociologia no Brasil, de uma maneira geral, o que ela tem feito é desenvolver uma agenda própria da Sociologia profissional, enfim, no sentido mais tradicional, e, ao mesmo tempo, ela tem construído uma face de políticas públicas dessa Sociologia profissional, que é uma forma de ela se legitimar frente ao Estado, a alguns investidores e a uma parcela da sociedade, em um momento em que a discussão sobre as políticas públicas está na ordem do dia, por conta dos programas de transferência de renda condicionada, em especial o Bolsa Família, e não apenas isso, pois você tem políticas públicas na área do trabalho, da violência urbana, de cultura. Está tudo muito imbricado e inter-relacionado. Eu vejo que a tendência, se ela se confirma como predominante, e esse é o horizonte que nós temos pela frente, é que o espaço para uma ciência social autônoma, crítica e reflexiva, ele tende a diminuir, isso não quer dizer que seja uma fatalidade, mas ele tende a diminuir por conta das características tanto do regime de produção de ciência e tecnologia quanto pelas próprias características desse tipo de conhecimento sociológico.

Revista Plural Voltando ao tema da Sociologia pública, você consegue apontar hoje alguém que pratica esse tipo de Sociologia no Brasil e no mundo? E um caso bem-sucedido, que você poderia considerar como um tipo ideal? Ruy Braga O Cenedic [Centro de Estudos dos Direitos da Cidadania] é um caso exemplar de Sociologia pública. Eu diria que há muitos casos muito bem-sucedidos de Sociologia pública. Internacionalmente, eu sempre cito um que eu gosto muito, o texto da Bárbara Enrehreich, que, no Brasil, foi publicado como Miséria à Americana, que é uma etnografia. A Bárbara Enrehreich, apesar de não ser socióloga, recebeu o prêmio de socióloga emérita da American Sociological Association. Ela não é socióloga de formação, ela 
é bióloga, mas trabalha como jornalista e sempre transitou muito na Sociologia. Ela fez um estudo etnográfico em várias situações de trabalho precário nos EUA; ela foi de tudo um pouco... Ela atuou como, por exemplo, garçonete, faxineira, como ajudante em um asilo, tomando conta de pessoas idosas, enfim, vários subempregos nos EUA. E, finalmente, ela foi trabalhar no Wall Mart e, no Wall Mart, que foi um pouco o coroamento dessa trajetória toda, ela escreveu o livro e lançou um debate que alcançou uma escala nacional nos EUA sobre o seguro saúde para os trabalhadores do Wall Mart. Isso forçou o Wall Mart a assumir os baixos salários, as péssimas condições de trabalho, e isso tudo criou uma ampla discussão nos EUA. E eu acho que esse é um exemplo absolutamente paradigmático de Sociologia pública bem-sucedida, um estudo sociológico que teve, ao mesmo tempo, uma repercussão pública e ensejou um debate que envolveu trabalhadores, movimentos sindicais, o próprio Service Employees International Union interveio nesse debate. Foi bem interessante e é um caso que vale a pena chamar a atenção para esse aspecto de que a Sociologia pública pode gerar debates interessantes.

\section{Revista Plural Você falou do CENEDIC no Brasil...}

Ruy Braga Ele tem tido essa tarefa. Talvez um exemplo bem-sucedido no Brasil de Sociologia pública seja o CENEDIC, com um profundo compromisso com pesquisa empírica, articulado com reflexão crítica, muito temperado pelo marxismo crítico, profano, aberto, antidogmático, pouquíssimo quadrado, enfim... O CENEDIC é um exemplo de Sociologia pública, tanto com as intervenções do Chico de Oliveira, os contatos que ele tem com os movimentos sociais e sindicais, mas também as pesquisas que a Vera faz na periferia, as pesquisas que a Cibele Rizek faz, as que eu faço e as que o Leo[nardo Mello e Silva] faz, tudo isso tem relação com a Sociologia pública. Vocês vão encontrar Sociologias públicas regionais com muita qualidade. Um exemplo muito interessante que eu sempre dou é o pessoal de Londrina: o laboratório que anima um seminário muito tradicional e bacana sobre as lutas sociais 
na América Latina, o Gepal [Grupo de Estudos de Política da América Latina]. Você encontra localmente muitos exemplos bem-sucedidos de Sociologia pública no Brasil e, ao mesmo tempo, você tem casos de sociólogos brasileiros atuando de forma muito intensa, como o caso do professor José de Souza Martins, com seus artigos em O Estado de São Paulo, um típico caso de Sociologia pública de perfil tradicional de alta qualidade. Vocês encontram exemplos muito bem-sucedidos, quer seja de Sociologia tradicional, orgânica, quer seja uma mistura dessas duas país afora.

Revista Plural Nós não falamos tanto sobre suas pesquisas no setor de serviços.

Ruy Braga Eu, durante uns quatro anos, desenvolvi pesquisas entre trabalhadores de dois setores de serviço o de supermercados, com os caixas e os atendentes, e o segundo é o setor de telemarketing (call-centers). Por uma série de motivos, o segundo acabou me absorvendo mais, e eu acabei produzindo mais sobre o setor de call-center, apesar de gostar muito da pesquisa no setor de supermercado, no setor de caixas, atendentes, o pessoal que trabalha nos depósitos, recolhe os produtos. e foi uma pesquisa bastante interessante. O livro saiu publicado no ano passado, chamado Infoproletários, e tenta dar conta um pouco disso. Os artigos que publiquei discutem a questão do taylorismo no setor de serviços, uma revivificação do taylorismo, não tanto no setor produtivo, mas mais no de serviços. E eu tentei, de alguma maneira, eu acho que aqui e ali eu tenho forçado a situação, ver nesses trabalhadores desses setores um microcosmo das transformações no mundo do trabalho brasileiro nas décadas de 1990 e 2000. E não apenas do ponto de vista da representatividade, no sentido de que eles representam tendências, que são próprias do mundo de trabalho brasileiro, do mercado de trabalho e das condições nas próprias empresas, como também um padrão de reprodução do trabalho no Brasil, que é a modernização que se nutre das formas mais arcaicas de discriminação, de exploração e mesmo de reprodução da 
força de trabalho. Então, você tem aí uma inter-relação muito interessante e rica em termos sociológicos e muito representativa do que é o mundo do trabalho no Brasil. É um pouco essa a minha preocupação, eu tenho me especializado um pouco nisso. E, ao mesmo tempo, eu tento desenvolver outras áreas nesse campo, como, por exemplo, a questão do movimento sindical no setor de telemarketing, que é um tema que me interessa cada vez mais. Eu acabei de apresentar um paper na ISA a esse respeito. Da mesma maneira, estudar a transformação do movimento sindical mais geral do Brasil tem me atraído também, um pouco a pauta e agenda de pesquisa do Cenedic. Isso tudo faz parte desse horizonte.

Revista Plural Seria uma tentativa de buscar um público para sua Sociologia? Ruy Braga Sem dúvida, porque as pesquisas que eu fiz no setor de serviços eu não conseguiria fazer sem a interlocução com os sindicatos. Essa sempre foi uma marca da minha vida, desde a graduação eu estou metido em sindicato, sempre tenho contato com os trabalhadores por meio dos sindicatos. Então, eu sou militante da Conlutas, que é uma central sindical, e isso faz parte do meu horizonte de interesse intelectual e investimento político, de construção teórico-política desse universo. O lançamento do livro foi lá no SinTel, lá no Rio de Janeiro. Já dei curso lá no SinTel, da mesma forma que tenho contatos aqui no Sintratel aqui em São Paulo, o sindicato dos trabalhadores de telemarketing.

Revista Plural Ainda nessa questão sobre ciência e militância, você acha que é mais difícil obter reconhecimento científico tendo um engajamento político? Ruy Braga Muito mais, sem dúvida nenhuma. O paradigma que predomina ainda é o paradigma positivista, que acha que as técnicas são neutras, a teoria é neutra. Isso tudo tem prestígio acadêmico, é o setor predominante da Sociologia no mundo inteiro, diga-se de passagem. Do ponto de vista da Sociologia profissional, é a dimensão instrumental do conhecimento sociológi- 
co que garante mais prestígio, verbas, financiamento, etc. O reconhecimento de que existem pressupostos políticos em qualquer prática científica, qualquer conhecimento primeiro de que a Sociologia é por definição ideológica, mesmo aquela que se acha neutra é ideológica, isso tudo não garante prestígio para ninguém; pelo contrário, garante oposição, resistência e inimizade.

\section{Revista Plural E como você lida com isso?}

Ruy Braga Fazendo a melhor Sociologia possível, com o refinamento das técnicas e com a reflexão crítica a propósito da teoria e dos métodos. É a única maneira, até porque, como marxista e como sociólogo, eu não posso não ter um compromisso com isso. Eu preciso ter um compromisso com a excelência dos métodos e das técnicas, só que eu sou o primeiro a reconhecer que os fundamentos teóricos da Sociologia são ideológicos. Não existe uma Sociologia neutra, tudo faz parte do mundo da política; existem as mediações a serem construídas, mas tudo é político. Nosso ambiente é profundamente saturado de política, da mesma maneira que as ciências exatas também, só que de outra forma.

Revista Plural Alguma colocação que você gostaria de fazer para concluir a entrevista?

Ruy Braga O que eu poderia acrescentar que eu já não disse? Olha, meu grande barato hoje é, sem dúvida nenhuma, meu grande desafio, meu grande estímulo está na construção de uma Sociologia pública marxista do trabalho no Brasil. A gente constrói lugares no mundo onde nós nos sentimos bem. Tem gente que se sente bem fazendo Sociologia mais profissional, mais concentrada no campo acadêmico, em que o diálogo circula mais em uma comunidade, etc., eu não me sinto bem fazendo esse tipo de Sociologia. Acho que o meu lugar na Sociologia é este: fazendo uma Sociologia pública marxista do trabalho no Brasil. E eu estou muito desafiado por essa agenda internacional da Sociologia pública, essa tentativa de estabelecer pontes, contatos en- 
tre o norte e o sul, estudos comparativos. Isso tem me fascinado bastante, e o antigo projeto do CENEDIC me deu oportunidade para pensar bastante, estabelecer contatos que têm sido muito profícuos: Edward Webster, Patrick Bond, Sakhela Buhlungu... Eles têm me oferecido oportunidades para refletir a propósito do Brasil em termos comparativos, algo que é bem legal. Isso tem me deixado muito estimulado. Eu acrescentaria isto: é um pouco esse o recado para nossos estudantes de Sociologia e pesquisadores daqui - existe hoje uma agenda internacional, diria até global da Sociologia pública, que tem desafiado os pesquisadores, que tem trazido um debate, e acho que valeria a pena a Sociologia brasileira romper com nosso ensimesmamento e ver o que está sendo discutido por essa Sociologia global. Acho que essa é uma boa maneira de encerrar nossa conversa, com um convite.

Revista Plural Muito obrigado. 